\title{
Measured irrigation: a significant development in water efficient irrigation
}

\author{
B. Omodei \\ Dot2dot, Australia
}

\begin{abstract}
This paper introduces a new method or irrigation called Measured Irrigation whereby one decides in advance the volume of water emitted from each emitter in each sector during the irrigation event. The volume emitted is independent of the pressure and independent of the length of the irrigation event. Measured Irrigation is gravity fed and may be unpowered or powered. A powered system may be automated and may be powered by a solar panel. Results are presented for trials designed to test the accuracy and uniformity of the volumes emitted. Keywords: irrigation systems, unpressurised, gravity feed, solar panel.
\end{abstract}

\section{Introduction}

This paper presents the results of trials designed to test the accuracy and uniformity of a new method of irrigation called Measured Irrigation. A paper entitled 'Measured Irrigation - An Introduction' has been submitted by Omodei [1] for publication in Irrigation and Drainage. To appreciate the significance of the trial results one needs to clearly understand the conceptual basis for Measured Irrigation. Hence, some on the content of Omodei [1] needs to be included in this paper.

With Measured Irrigation one decides in advance how much water each plant requires and Measured Irrigation delivers the required volume of water to each plant. Hence one knows in advance the total water requirement during the irrigation event for one's garden, orchard, crop or nursery.

Measured Irrigation does not require access to mains water or mains power. All that is required is rainwater and sunlight, and so there are no ongoing costs for water and electricity. A 20 watt solar panel and an above ground water tank can deliver up to 450 litres per hour to the flow splitter.

Measured Irrigation is completely scalable and so it can be adapted to small and large irrigation applications. For example, it can be used to automatically 
water indoor plants or it can be used to automatically irrigate thousands of seedlings in a large commercial nursery. Nurseries may dramatically reduce their water bills by watering each seedling with the appropriate amount of water with minimal wastage.

Pressurised drip irrigation systems are able to control the volume of water emitted from a dripper during the irrigation event by controlling both the flow rate from the dripper and the length of the irrigation event. The flow rate is controlled by pressure compensating drippers. This approach requires the control of two parameters (flow rate and time) in order to control the volume.

Measured Irrigation is an unpressurised gravity-feed irrigation system that controls a single parameter only, namely the volume of water emitted from each nozzle in each sector during the irrigation event without the need to control the flow rate or the length of the irrigation event. The flow rate and the length of the irrigation event adjust automatically to ensure that the correct volume of water is emitted by each nozzle.

The vast majority of microirrigation systems are pressurised with pressures in excess of $100 \mathrm{kPa}$. For unpressurised (or gravity feed) systems the pressure at the emitters need to be at least $10 \mathrm{kPa}$ [2]. With Measured Irrigation the pressure at the emitters may be as low as $1 \mathrm{kPa}$.

Measured Irrigation is installed at the following locations in Adelaide: Fern Ave Community Garden in the City of Unley, Prospect Community Garden in the City of Prospect, Windsor Gardens Vocational College, Provenance Nursery and at 50 Harvey Street Woodville Park.

A patent for Measured Irrigation has been applied for [3].

\section{Unpowered measured irrigation}

For each irrigation sector one can use either nozzles or porous hose. A nozzle is a short cylindrical tube attached to a lateral and delivering a measured volume of water to a plant or group of plants. Because Measured Irrigation is gravity fed, a porous hose sector needs to use a special porous hose that is effective for pressures as low as $1 \mathrm{kPa}$. The porous hose used by pressurised irrigation systems is totally unsuitable.

Figure 1 illustrates schematically a basic unpowered Measured Irrigation system with one nozzle sector and one porous hose sector. During the irrigation event, the water level in the flow splitter is stabilised by adjusting the inlet valve. The control nozzle attached to the flow splitter delivers a fixed volume of water to the evaporator. The irrigation nozzles attached to the flow splitter deliver a measured volume of water to the irrigation sectors. The irrigation nozzles and the control nozzle are at the same level, and hence at the same pressure. Therefore the volume of water delivered to each sector during the irrigation event depends only on the ratio of the flow rate of the irrigation nozzle to the flow rate of the control nozzle. 


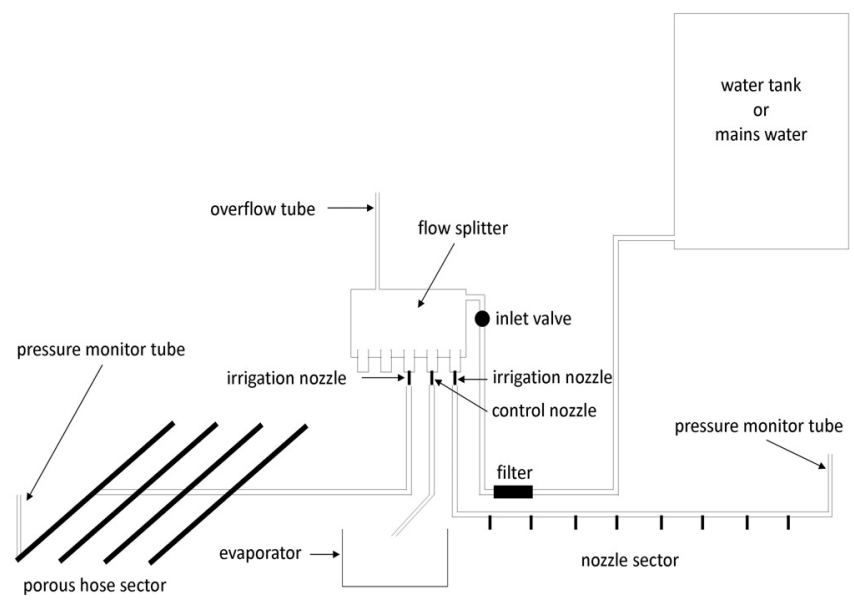

Figure 1: Schematic diagram of unpowered Measured Irrigation showing one nozzle sector and one porous hose sector.

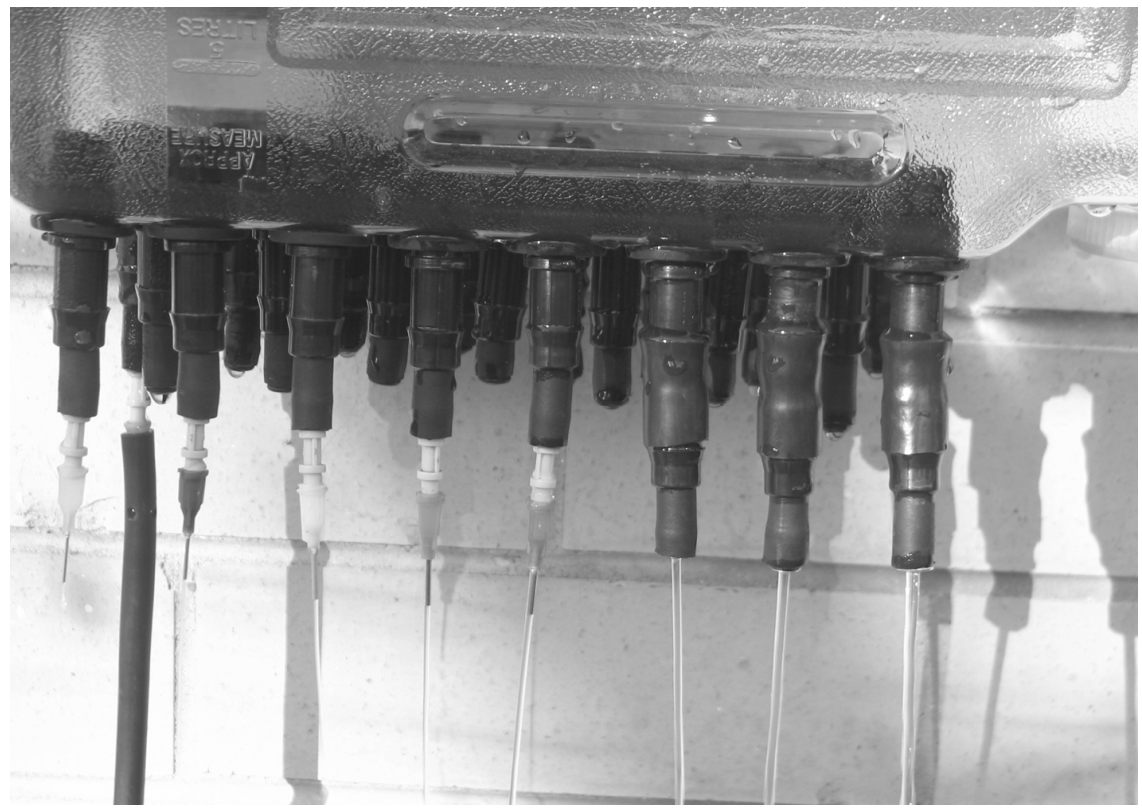

Figure 2: Irrigation nozzles attached to the flow splitter and the control nozzle with tube attached. 


\section{The nozzle formula}

Measured Irrigation is the application of the nozzle formula. The nozzle formula states that:

where

measured volume $=$ control volume $\mathrm{x}$ nozzle ratio

measured volume is the volume of water delivered by the irrigation nozzle on the flow splitter during the irrigation event, control volume is the volume of water delivered by the control nozzle to the evaporator during the irrigation event, and

nozzle ratio is the ratio of the flow rate of the irrigation nozzle to the flow rate of the control nozzle when both nozzles are at the same pressure.

The nozzle ratio is a characteristic of the nozzles and independent of the flow rate. Therefore the nozzle formula is independent of the flow rate. Therefore the volume of water delivered to any irrigation sector during the irrigation event is independent of the flow rate. The water level in the flow splitter can rise and fall without affecting the irrigation volumes.

The accuracy and uniformity of pressurised drip irrigation depends on the fabrication of accurate pressure compensating drippers. For Measured Irrigation no pressure compensation is required.

\section{Porous hose sector}

For some applications of Measured Irrigation, a special porous hose made from recycled car tyres provides an ideal delivery mechanism (it is economical, it is easy to install, it does not get blocked and it prevents root invasion). However, the current manufacturing process for porous hose does not produce uniform porosity along the length of the hose $[4,5]$. This non-uniformity in the porosity of the hose can be a serious limitation.

Furthermore, the use of porous hose for pressurised systems has the additional disadvantage of serious frictional head loss along the length of the hose. The issue of head loss is closely related to the pressure in the hose. However, for an unpressurised system such as Measured Irrigation, head loss can be easily accommodated by limiting the length of the porous hose laterals.

When one uses special porous hose for Measured Irrigation, one may compensate for non-uniformity by increasing the volume of water discharged by the hose within a sector.

\section{Nozzle sector}

The nozzle formula is used to predict the volume of water delivered to a sector during the irrigation event. To predict the volume of water emitted by a nozzle within a sector we need to use the extended nozzle formula [1].

For a particular sector assume that there are $\mathrm{N}$ emitter nozzles at the same level with nozzle ratios $R_{1}, R_{2}, \ldots, R_{N}$ and that the volumes of water emitted by the nozzles are $\mathrm{V}_{1}, \mathrm{~V}_{2}, \ldots, \mathrm{V}_{\mathrm{N}}$. 
The extended nozzle formula states that:

where

$$
\mathrm{V}_{\mathrm{i}}=\mathrm{V}_{\mathrm{c}} * \mathrm{R} * \mathrm{R}_{\mathrm{i}} /\left(\mathrm{R}_{1}+\mathrm{R}_{2}+\ldots+\mathrm{R}_{\mathrm{N}}\right) \quad \mathrm{i}=1,2, \ldots, \mathrm{N}
$$

$\mathrm{V}_{\mathrm{c}}$ is the control volume and

$\mathrm{R}$ is the nozzle ratio for the irrigation nozzle for the sector.

For some applications it may be appropriate to use a hierarchy of flow splitters where the output from a flow splitter at one level becomes the input for a flow splitter at a lower level. The nozzle formula is used to determine the volumes of water emitted by the nozzles on the top level flow splitter, and the extended nozzle formula is used to determine the volumes of water emitted by the nozzles on the lower level flow splitters.

\section{Powered measured irrigation}

Powered Measured Irrigation is completely automatic.

The evaporator is installed in a suitable location near the plants to be irrigated. The irrigation event commences when the water level in the evaporator falls below the low probe. The irrigation event ends when the water level reaches the high probe. The evaporator and level sensor are shown in Figure 3.

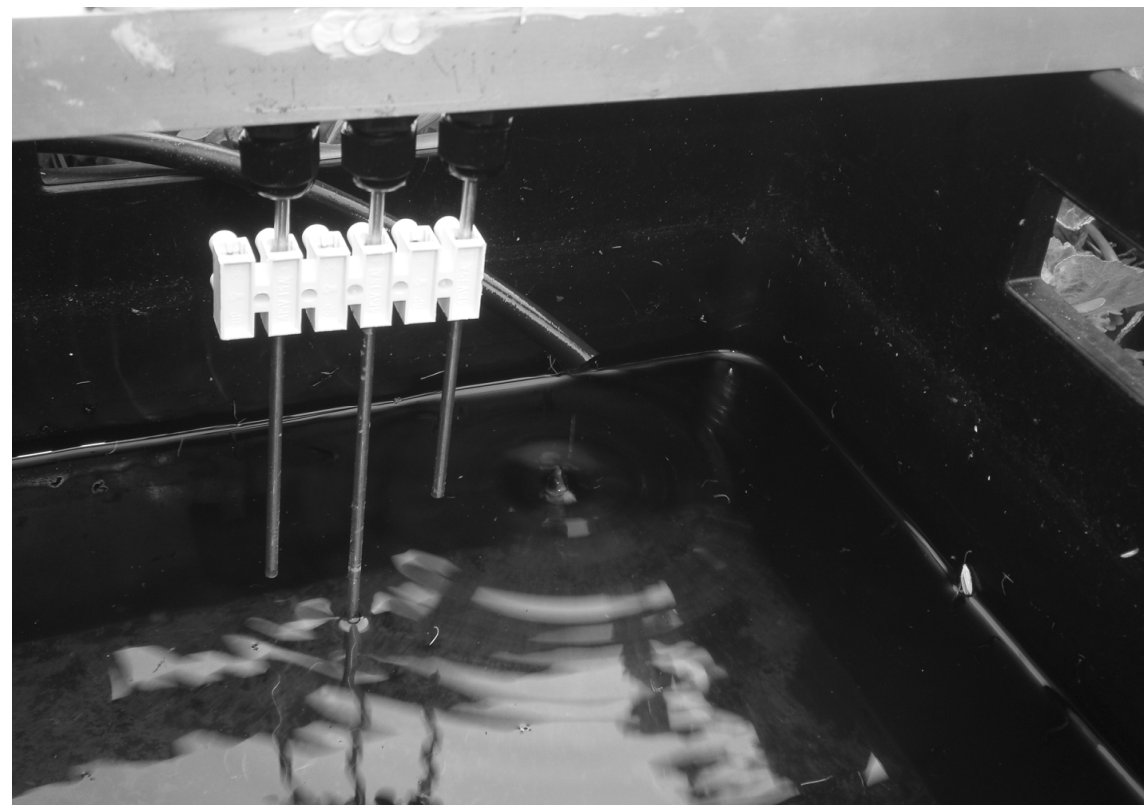

Figure 3: Image showing water dripping into the evaporator from the control nozzle via the tube. The high probe is on the right, the low probe is one the left and the reference probe is in the middle. Irrigation stops when water reaches the high probe, and irrigation recommences when water falls below the low probe. 
The irrigation down time is the time it takes for the water level in the evaporator to fall (due to evaporation) from the high level at the end of the irrigation event to the low level (low probe). One can increase or decrease the irrigation down time by increasing or decreasing the number of millimetres between the high probe and the low probe (the probe lengths are adjustable).

The irrigation down time is also influenced by the prevailing weather conditions. During very hot weather the evaporation rate will be much greater and so the irrigation down time will be shorter. On cool overcast days, the evaporation rate will be quite small and so the irrigation down time will be longer. When it rains the water level in the evaporator rises and delays the start of the next irrigation event.

In order for Measured Irrigation to accurately predict the volume of water delivered to each sector and the volume of water delivered to each plant within each sector, one needs to accurately measure the control volume (see Omodei [1] for details).

\section{Methodology}

All of the trials presented in this paper are designed to test the accuracy and uniformity of Measured Irrigation for nozzle sectors. We will first discuss the methodology for nozzle sectors where all of the nozzles are the same, and then generalize the methodology to include sectors where the nozzles are different.

When all the nozzles are the same, we will measure the accuracy of the mean emitter volume compared with the predicted emitter volume. We will also measure the uniformity of the emitter volumes with respect to the mean emitter volume.

Let us define the accuracy of the mean (AM) by the formula

where

$$
\mathrm{AM}=100 *(1-|\mathrm{M}-\mathrm{P}| / \mathrm{M})
$$

$\mathrm{M}$ is the mean emitter volume, and

$\mathrm{P}$ is the predicted emitter volume.

The uniformity results will be presented using 3 different definitions of uniformity. All the definitions are equivalent to those used in Lamm et al. [6].

Christiansen uniformity (CU) is defined by the formula

where

$$
\mathrm{CU}=100 *\left(1-\left(\sum\left|\mathrm{V}_{\mathrm{i}}-\mathrm{M}\right|\right) / \mathrm{N} / \mathrm{M}\right)
$$

the summation is for all emitter volumes $V_{i}$ for $i=1,2, \ldots, N$,

$\mathrm{N}$ is the number of emitters, and

$\mathrm{M}$ is the mean emitter volume.

Statistical uniformity (SU) is defined by the formula

$$
\left.\mathrm{SU}=100 *\left(1-\left(\sum\left(\mathrm{V}_{\mathrm{i}}-\mathrm{M}\right)^{2}\right) / \mathrm{N}\right)^{1 / 2} / \mathrm{M}\right)
$$

Distribution uniformity (DU) is defined by the formula

where

$$
\mathrm{DU}=\left(100 * \mathrm{M}_{25}\right) / \mathrm{M}
$$

$\mathrm{M}_{25}$ is the mean emitter volume for the lowest $25 \%$ of measurements, and

$\mathrm{M}$ is the mean emitter volume for all the measurements. 
Christiansen uniformity (CU) and accuracy of the mean (AM) can be combined into a measure of both uniformity and accuracy, namely Christiansen uniformity with respect to the predicted emitter volume (CUP) which is defined by the formula

$$
\mathrm{CUP}=100 *\left(1-\left(\sum\left|\mathrm{V}_{\mathrm{i}}-\mathrm{P}\right|\right) / \mathrm{N} / \mathrm{P}\right)
$$

Similarly, statistical uniformity (SU) and accuracy of the mean (AM) can be combined into a measure of both uniformity and accuracy, namely statistical uniformity with respect to the predicted emitter volume (SUP) which is defined by the formula

$$
\text { SUP } \left.=100 *\left(1-\left(\sum\left(\mathrm{V}_{\mathrm{i}}-\mathrm{P}\right)^{2}\right) / \mathrm{N}\right)^{1 / 2} / \mathrm{P}\right)
$$

Let us now develop a methodology for measuring the accuracy and uniformity of Measured Irrigation where the nozzles are different. Christiansen uniformity with respect to the predicted emitter volume (CUP) can be generalised to measure the accuracy and uniformity when the nozzles are different. The generalised formula is

$$
\text { CUP }=100 *\left(1-\left(\sum\left|\mathrm{V}_{\mathrm{i}}-\mathrm{P}_{\mathrm{i}}\right| / \mathrm{P}_{\mathrm{i}}\right) / \mathrm{N}\right)
$$

where

$\mathrm{P}_{\mathrm{i}}$ is the predicted emitter volume corresponding to the measured emitter volume $\mathrm{V}_{\mathrm{i}}$ for $\mathrm{i}=1,2, \ldots, \mathrm{N}$.

Similarly, statistical uniformity with respect to the predicted emitter volume (SUP) can be generalised to measure the accuracy and uniformity when the nozzles are different. The generalised formula is

$$
\left.\mathrm{SUP}=100 *\left(1-\left(\sum\left(\mathrm{V}_{\mathrm{i}}-\mathrm{P}_{\mathrm{i}}\right)^{2} / \mathrm{P}_{\mathrm{i}}^{2}\right) / \mathrm{N}\right)^{1 / 2}\right)
$$

\section{Results}

Results are presented for two nozzle sectors.

\section{Sector 1}

A 30 metre long garden bed has 40 nozzles, uniformly spaced along a 30 metre length of $19 \mathrm{~mm}$ polypipe. For nine trials the nozzles are the same. Progressing from the smallest diameter nozzle to the largest diameter nozzle, the nozzle colours are black, green, yellow, brown, pink, white, purple, orange and olive. The tenth trial uses 36 nozzles, 4 of each of the 9 different colours.

The results of trials 1 to 9 are presented in Tables 1 and 2 .

The tenth trial uses 36 nozzles, 4 of each of the 9 different colours. The accuracy and uniformity of the results can be measured by Christiansen uniformity with respect to predicted emitter volume (CUP) and statistical uniformity with respect to predicted emitter volume (SUP).

$$
\begin{aligned}
& \text { CUP }=89 \% \\
& \text { SUP }=92 \%
\end{aligned}
$$

Further trials with similar results are reported in Omodei [7] and Chand [8].

In summary, the results of the trails reported above and those of [7] and [8] indicate that the accuracy and uniformity of Measured Irrigation is generally better than $90 \%$. 
Table 1: $\quad$ Results of 9 trials for sector 1 showing accuracy of the mean (AM), Christiansen uniformity (CU), statistical uniformity (SU) and distribution uniformity (DU).

\begin{tabular}{|c|c|c|c|c|c|c|}
\hline & $\mathrm{P}$ & $\mathrm{M}$ & $\mathrm{AM}$ & $\mathrm{CU}$ & $\mathrm{SU}$ & DU \\
\hline $\begin{array}{c}\text { nozzle } \\
\text { and ID }\end{array}$ & $\begin{array}{c}\text { predicted } \\
\text { volume }\end{array}$ & $\begin{array}{c}\text { mean } \\
\text { volume }\end{array}$ & $\begin{array}{c}\text { accuracy of the } \\
\text { mean }\end{array}$ & $\begin{array}{c}\text { Christiansen } \\
\text { uniformity }\end{array}$ & $\begin{array}{c}\text { statistical } \\
\text { uniformity }\end{array}$ & $\begin{array}{c}\text { distribution } \\
\text { uniformity }\end{array}$ \\
\hline $\begin{array}{c}\text { black } \\
0.51 \mathrm{~mm}\end{array}$ & $0.77 \mathrm{~L}$ & $0.74 \mathrm{~L}$ & $97 \%$ & $93 \%$ & $93 \%$ & $92 \%$ \\
\hline $\begin{array}{c}\text { green } \\
0.56 \mathrm{~mm}\end{array}$ & $1.24 \mathrm{~L}$ & $1.18 \mathrm{~L}$ & $95 \%$ & $92 \%$ & $92 \%$ & $91 \%$ \\
\hline $\begin{array}{c}\text { yellow } \\
0.63 \mathrm{~mm}\end{array}$ & $0.91 \mathrm{~L}$ & $0.93 \mathrm{~L}$ & $98 \%$ & $96 \%$ & $95 \%$ & $93 \%$ \\
\hline $\begin{array}{c}\text { brown } \\
0.84 \mathrm{~mm}\end{array}$ & $1.95 \mathrm{~L}$ & $1.99 \mathrm{~L}$ & $98 \%$ & $93 \%$ & $93 \%$ & $92 \%$ \\
\hline $\begin{array}{c}\text { pink } \\
0.97 \mathrm{~mm}\end{array}$ & $7.88 \mathrm{~L}$ & $8.02 \mathrm{~L}$ & $98 \%$ & $91 \%$ & $88 \%$ & $88 \%$ \\
\hline $\begin{array}{c}\text { white } \\
1.22 \mathrm{~mm}\end{array}$ & $3.84 \mathrm{~L}$ & $3.70 \mathrm{~L}$ & $96 \%$ & $93 \%$ & $93 \%$ & $90 \%$ \\
\hline $\begin{array}{c}\text { purple } \\
1.35 \mathrm{~mm}\end{array}$ & $3.61 \mathrm{~L}$ & $3.55 \mathrm{~L}$ & $98 \%$ & $91 \%$ & $91 \%$ & $88 \%$ \\
\hline $\begin{array}{c}\text { orange } \\
1.50 \mathrm{~mm}\end{array}$ & $3.13 \mathrm{~L}$ & $3.06 \mathrm{~L}$ & $98 \%$ & $90 \%$ & $89 \%$ & $85 \%$ \\
\hline $\begin{array}{c}\text { olive } \\
1.75 \mathrm{~mm}\end{array}$ & $2.86 \mathrm{~L}$ & $3.08 \mathrm{~L}$ & $93 \%$ & $91 \%$ & $91 \%$ & $88 \%$ \\
\hline
\end{tabular}

Table 2: $\quad$ Results of 9 trials for Sector 1 showing Christiansen uniformity with respect to predicted emitter volume (CUP) and statistical uniformity with respect to predicted emitter volume (SUP).

\begin{tabular}{|c|c|c|c|c|}
\hline $\begin{array}{c}\text { nozzle } \\
\text { and ID }\end{array}$ & $\begin{array}{c}\text { predicted } \\
\text { volume }\end{array}$ & mean volume & $\begin{array}{c}\text { Christiansen } \\
\text { uniformity wrt } \\
\text { predicted }\end{array}$ & $\begin{array}{c}\text { statistical uniformity } \\
\text { wrt predicted }\end{array}$ \\
\hline $\begin{array}{c}\text { black } \\
0.51 \mathrm{~mm}\end{array}$ & $0.77 \mathrm{~L}$ & $0.74 \mathrm{~L}$ & $92 \%$ & $83 \%$ \\
\hline $\begin{array}{c}\text { green } \\
0.56 \mathrm{~mm}\end{array}$ & $1.24 \mathrm{~L}$ & $1.18 \mathrm{~L}$ & $91 \%$ & $82 \%$ \\
\hline $\begin{array}{c}\text { yellow } \\
0.63 \mathrm{~mm}\end{array}$ & $0.91 \mathrm{~L}$ & $0.93 \mathrm{~L}$ & $95 \%$ & $94 \%$ \\
\hline $\begin{array}{c}\text { brown } \\
0.84 \mathrm{~mm}\end{array}$ & $1.95 \mathrm{~L}$ & $1.99 \mathrm{~L}$ & $92 \%$ & $80 \%$ \\
\hline $\begin{array}{c}\text { pink } \\
0.97 \mathrm{~mm}\end{array}$ & $7.88 \mathrm{~L}$ & $8.02 \mathrm{~L}$ & $90 \%$ & $82 \%$ \\
\hline $\begin{array}{c}\text { white } \\
1.22 \mathrm{~mm}\end{array}$ & $3.84 \mathrm{~L}$ & $3.70 \mathrm{~L}$ & $93 \%$ & $82 \%$ \\
\hline $\begin{array}{c}\text { purple } \\
1.35 \mathrm{~mm}\end{array}$ & $3.61 \mathrm{~L}$ & $3.55 \mathrm{~L}$ & $91 \%$ & $80 \%$ \\
\hline $\begin{array}{c}\text { orange } \\
1.50 \mathrm{~mm}\end{array}$ & $3.13 \mathrm{~L}$ & $3.06 \mathrm{~L}$ & $91 \%$ & $88 \%$ \\
\hline olive $1.75 \mathrm{~mm}$ & $2.86 \mathrm{~L}$ & $3.08 \mathrm{~L}$ & & \\
\hline
\end{tabular}




\section{Sector 2}

This sector was setup at the Australian Irrigation Technology Centre at the University of South Australia. The uniformity of Measured Irrigation is compared with the uniformity of conventional drip irrigation using pressure compensating drippers. For all trials 20 emitters were used, uniformly spaced along a 20 metre length of $13 \mathrm{~mm}$ polypipe. The trials were conducted as part of a student research project by Oyon [9] and the results are presented in Table 3.

Table 3: $\quad$ Results of 11 trials for Sector 2 with 8 trials for Measured Irrigation and 3 trials for drip irrigation. Christiansen uniformity (CU), statistical uniformity (SU) and distribution uniformity (DU) are reported.

\begin{tabular}{|c|c|c|c|c|c|c|}
\hline Trial \# & Emitter & Pressure & $\begin{array}{c}\text { Mean flow } \\
\text { rate }\end{array}$ & \begin{tabular}{|c|} 
Christiansen \\
uniformity \\
CU
\end{tabular} & $\begin{array}{c}\text { Statistical } \\
\text { uniformity } \\
\text { SU }\end{array}$ & $\begin{array}{c}\text { Distribution } \\
\text { uniformity } \\
\text { DU }\end{array}$ \\
\hline \multicolumn{7}{|c|}{ Measured Irrigation } \\
\hline 1 & $\begin{array}{c}4.2 \text { rivet } \\
\text { nozzle }\end{array}$ & $5 \mathrm{kPa}$ & $0.79 \mathrm{~L} / \mathrm{h}$ & $92 \%$ & $90 \%$ & $86 \%$ \\
\hline 2 & $\begin{array}{c}4.2 \text { rivet } \\
\text { nozzle }\end{array}$ & $5 \mathrm{kPa}$ & $0.85 \mathrm{~L} / \mathrm{h}$ & $92 \%$ & $90 \%$ & $86 \%$ \\
\hline 3 & $\begin{array}{c}4.2 \text { rivet } \\
\text { nozzle }\end{array}$ & $5 \mathrm{kPa}$ & $0.84 \mathrm{~L} / \mathrm{h}$ & $91 \%$ & $89 \%$ & $85 \%$ \\
\hline 4 & $\begin{array}{c}4.2 \text { rivet } \\
\text { nozzle }\end{array}$ & $5 \mathrm{kPa}$ & $0.86 \mathrm{~L} / \mathrm{h}$ & $91 \%$ & $88 \%$ & $84 \%$ \\
\hline 5 & $\begin{array}{c}5.4 \text { rivet } \\
\text { nozzle }\end{array}$ & $5 \mathrm{kPa}$ & $1.70 \mathrm{~L} / \mathrm{h}$ & $93 \%$ & $91 \%$ & $88 \%$ \\
\hline 6 & $\begin{array}{c}5.4 \text { rivet } \\
\text { nozzle }\end{array}$ & $5 \mathrm{kPa}$ & $1.69 \mathrm{~L} / \mathrm{h}$ & $96 \%$ & $94 \%$ & $92 \%$ \\
\hline 7 & $\begin{array}{c}5.4 \text { rivet } \\
\text { nozzle }\end{array}$ & $5 \mathrm{kPa}$ & $1.70 \mathrm{~L} / \mathrm{h}$ & $94 \%$ & $91 \%$ & $89 \%$ \\
\hline 8 & $\begin{array}{c}5.4 \text { rivet } \\
\text { nozzle }\end{array}$ & $5 \mathrm{kPa}$ & $1.70 \mathrm{~L} / \mathrm{h}$ & $94 \%$ & $92 \%$ & $90 \%$ \\
\hline \multicolumn{7}{|c|}{ Drip Irrigation } \\
\hline 9 & $\begin{array}{c}4 \mathrm{~L} / \mathrm{h} \text { PC } \\
\text { dripper }\end{array}$ & $180 \mathrm{kPa}$ & $4.95 \mathrm{~L} / \mathrm{h}$ & $77 \%$ & $70 \%$ & $79 \%$ \\
\hline 10 & $\begin{array}{c}4 \mathrm{~L} / \mathrm{h} \text { PC } \\
\text { dripper }\end{array}$ & $240 \mathrm{kPa}$ & $4.77 \mathrm{~L} / \mathrm{h}$ & $82 \%$ & $76 \%$ & $83 \%$ \\
\hline 11 & $\begin{array}{c}4 \mathrm{~L} / \mathrm{h} \mathrm{PC} \\
\text { dripper }\end{array}$ & $240 \mathrm{kPa}$ & 4.49 L/h & $88 \%$ & $81 \%$ & $87 \%$ \\
\hline
\end{tabular}




\section{Conclusion}

The uniformity of Measured Irrigation is significantly better than the uniformity of drip irrigation. It is important to note that the pressure compensating drippers used for the comparison are a popular brand used throughout Australia.

For all the trials reported above and also for trials reported in [7] and [8], the accuracy and uniformity of Measured Irrigation is generally better than $90 \%$.

Measured Irrigation is an unpressurised gravity-feed irrigation system that controls a single parameter only, namely the volume of water emitted from each nozzle in each sector during the irrigation event without the need to control the flow rate or the length of the irrigation event.

Measured Irrigation may be the most significant development in water efficient irrigation since drip irrigation

\section{References}

[1] Omodei, B.J., Measured Irrigation - An Introduction. Submitted to Irrigation and Drainage, 2012.

[2] IDE International Development Enterprise, Technical manual for ideal microirrigation systems. IDE \& CGIAR Challenge Program for Water and Food, 2011.

[3] Omodei, B.J., Measured Irrigation. Provisional Patent Application No. 2012900492, IP Australia, 2012.

[4] Smajstrla, A.G., Field studies of porous pipe micro-irrigation laterals. ASAE Paper No. 92-2089. ASAE International Summer Meeting, 21-24 June, Charlotte, NC, 1992.

[5] Yoder, R.E. and Mote, C.R., Porous Pipe Discharge Uniformity. Microirrigation for a Changing World. Proc. Fifth International Micro-irrigation Congress, Orlando, Florida, 1995.

[6] Lamm, F.R., Ayars, J.E. and Nakayama, F.S., (eds). Microirrigation for Crop Production, Elsevier: Amsterdam, Netherlands, 2007.

[7] Omodei, B.J., Measured Irrigation. 7th Asian ICID Regional Conference, Adelaide, Australia, 2012.

[8] Chand, J.B., Evaluation of an Automated and Low-cost Measured Irrigation System. Major Industry Project for Master of Water Resources Management, School of Natural and Built Environments, University of South Australia, 2012.

[9] Oyon, C., Research Report. Australian Irrigation Technology Centre, University of South Australia, July 2012. 